\title{
Free Cinema: \\ O Elogio do Homem Comum
}

Cecilia Antakly de Mello

Pós-doutoranda - ECA-USP - Bolsa Fapesp 


\section{Resumo}

Este artigo investiga o movimento documentarista "Free Cinema", que integrou a onda de renovação do cinema inglês durante o período pós-Segunda Guerra Mundial. "Free Cinema" é o nome de uma mostra de filmes organizada em fevereiro de 1956 no National Film Theatre em Londres, e reiterada por outras cinco vezes até a derradeira sexta edição em março de 1959. O termo se refere também ao movimento iniciado pelos diretores Lindsay Anderson, Karel Reisz e Tony Richardson, organizadores da primeira mostra (como veículo de divulgação de seus filmes) e autores do 'manifesto por um cinema livre', uma reação vigorosa à estagnação do cinema inglês nos anos 1950. O artigo, além de traçar um rápido panorama do cinema inglês do pós-guerra, oferece uma discussão sobre a especificidade do realismo do Free Cinema, ligado a uma preocupação essencial com a vida quotidiana do 'homem comum'.

\section{Palavras-chave}

Cinema, Free Cinema, Cinema Inglês.

\section{Abstract}

This article investigates the Free Cinema documentary movement, which integrated the wave of renovation of English cinema during the post-war period. 'Free Cinema' was the name of a series of exhibitions organised from February 1956 at the National Film Theatre in London, followed by another five exhibitions until the sixth and last Free Cinema in 1959. The term also refers to the movement initiated by the filmmakers who organised the exhibitions (in a first instance as a vehicle for their debut films), and who wrote and signed a manifesto, expressing their views on filmmaking and vigorously reacting against the stagnation of English cinema in the 1950s. As well as presenting an overview of post-war English cinema's landscape, the article offers a discussion on the specificity of Free Cinema's realism, closely linked to an essential preoccupation with everyday life and the common man.

\section{Keywords}

Cinema, Free Cinema, British Cinema. 
pós o fim da Segunda Guerra Mundial em 1945, o cinema
inglês enfrentou o desafio estético da articulação do quotidiano
das classes trabalhadoras do país. Esta "aspiração ao realismo" assumiu formas diversas e se fez aparente por cerca de duas décadas, em ciclos de filmes de ficção, na televisão e no documentário. Pode-se destacar como os principais momentos desta dita "aspiração ao realismo", entre 1945 e 1965, o ciclo de filmes de fiçção denominado spiv films, que se desenvolveu em Londres entre 1945 e 1950; os documentários do Free Cinema, que surgiram entre 1956 e 1959; os ditos kitchen-sink dramas, também conhecidos por British New Wave, ciclo que durou de 1958 a 1963; e finalmente os teledramas, realizados principalmente para o programa Armchair Theatre na rede independente $\mathrm{ABC}$ e para o programa Wednesday Play na BBC 1 durante a década de 1960.

Estes quatro momentos pertencem a um amplo período de transição cultural, intrinsecamente ligado ao forte impacto histórico da Segunda Guerra Mundial. Em outras palavras, a nova conjuntura histórica produzida pela Guerra demandava a articulação de uma nova língua - ou novas línguas - mais aptas a abordar e responder à realidade do pós-guerra. Este texto apresenta uma visão geral do Free Cinema - ou Cinema Livre - a partir de uma contextualização histórica, uma investigação de seus alicerces teóricos e principais influências, chegando por fim à especificidade de seu realismo e a alguns exemplos principais. 
A partir dos anos 1940, o cinema inglês incorporou um importante movimento de extensão social através do qual a classe trabalhadora, até então relegada a papéis menores ou estereotipados, passou gradualmente a ocupar o centro da tela. Esta "extensão social da representação", nos termos de Raymond Williams (1977, p. 63), pode ser vista como o corolário natural do chamado "espírito igualitário" dos anos da Guerra. Talvez não tenha havido outro momento na história inglesa com um efeito similar, ou ao menos com a mesma intensidade. A Segunda Guerra afetou o dia-a-dia da população do país independentemente de classe, gênero ou etnia. A nação parecia estar unida, e por volta de 1940 o termo "guerra do povo" (people's war) já sugeria uma mudança de percepção. É evidente que a Guerra não provocou uma verdadeira revolução social, mas o sentimento de crise coletiva que assolou o país contribuiu para a dissimulação das mais aparentes distinções de classe da sociedade inglesa.

De fato, a Segunda Guerra Mundial, apesar de não ter erodido o sistema de classes do país, foi ao menos responsável pela maior visibilidade da classe trabalhadora durante o período do pós-guerra. Esta maior visibilidade foi mais do que nunca reforçada pelos seis anos de governo trabalhista que sucederam o fim da guerra, sob a liderança do Primeiro Ministro Clement Attlee (1945 a 1951). Durante os anos 1950, este fenômeno refletiu-se nas tendências populistas que gradualmente passaram a ditar diversas correntes artísticas na Inglaterra, fazendo com que aos poucos o termo "cultura da classe trabalhadora" deixasse de ser visto como uma contradição.

A revigorante aspiração ao realismo das diversas tendências do cinema e televisão ingleses durante o pós-guerra veio desafiar outra noção de realismo cinematográfico. Tratava-se do realismo de gênero, de cunho educacional e propagandístico, sedimentado durante os anos 1930 e 1940. A supremacia desta idéia de realismo havia também contaminado a noção de um cinema nacional. A dita "autêntica representação" do país significava então o legítimo cinema inglês, desenvolvido através de um intenso envolvimento do Estado na forma de propaganda para o esforço de Guerra. Realismo se opunha ao esteticismo e também ao entretenimento dos filmes 
americanos. Esta visão bipolar do cinema sugeria que realismo era não apenas superior como também genuíno e nacional, relegando a sofisticação visual a algo condenável e estrangeiro. Isso também tornava obscuros os aspectos ou inovações estéticas dos filmes realistas, valorizados apenas pelo seu conteúdo.

No contexto inglês, o ímpeto da responsabilidade social e o da inovação estética parecem ter coexistido de forma oposta desde os tempos de John Grierson. Apesar da inegável contribuição estética do movimento documentarista britânico da década de 1930 , é justo dizer que sua preocupação formal sempre esteve amplamente sujeita a uma fé na feição educacional do documentário. Nas palavras do próprio Grierson, "deve-se lembrar que o movimento documentarista britânico iniciou-se não tanto por uma afeição ao cinema per se, e sim por uma afeição à educação nacional. Se eu posso ser considerado o fundador e líder do movimento, suas origens certamente estão em fins sociológicos e não estéticos." ' (citado em Hardy, 1946, p. 140) Durante os anos 1940 e a primeira metade dos anos 1950, o realismo não apenas cinematográfico como também literário se reafirmou como a expressão natural da inclinação e tradição empírica e liberal humanista inglesa. Experimentalismo e inovação estética eram vistos como isolacionistas e condenáveis.

Os filmes responsáveis pela revitalização do cinema inglês no pós-guerra, incluindo o Free Cinema, emergiram então em uma cultura dominada por uma noção bipolar de cinema, que privilegiava uma abordagem utilitária em detrimento da idéia do cinema como arte ou entretenimento. Não há dúvida, como já apontado anteriormente, que as novas tendências do cinema e da televisão ingleses incorporaram um importante movimento de extensão social ao se voltarem gradualmente para a classe trabalhadora e seu ambiente. Entretanto, uma análise mais cuidadosa deste período deixa

1. Texto original: "It is worth recalling that the British documentary group began not so much in affection for film per se as in affection for national education. If I am to be counted as the founder and leader uf the movement, its origins certainly lay in sociological rather than aesthetic aims." 
claro que seu realismo não está apenas na noção de responsabilidade social, mas sim na questão formal, que constitui sua real motivação. Em outras palavras, apesar de representar uma mudança de atitude em relação à classe trabalhadora inglesa no pós-guerra, este cinema deriva também de um desafio: a busca por novos modos de articular a realidade em uma nova conjuntura histórica. Forma e conteúdo estavam desta feita ligados por um impulso similar, o de "falar" e "ouvir" a demótica, a língua do bar, da rua, da fábrica, dos parques de diversão, ou seja, as línguas do dia-a-dia.

Foi então neste cenário que surgiram os documentários do Free Cinema. De 5 a 8 de fevereiro de 1956, o National Film Theatre de Londres apresentou um programa de três filmes introduzidos por um manifesto, impresso no folheto da programação. Tratava-se de O Dreamland, de Lindsay Anderson, Momma Don't Allow, de Karel Reisz e Tony Richardson, e Together, da italiana Lorenza Mazzetti. Os quatro diretores chamaram o programa de Free Cinema e assinaram o manifesto que o lançou. $\mathrm{O}$ sucesso do primeiro programa deu ensejo a outros cinco, e finalmente o Free Cinema chegou ao fim em 1959 com o programa 6. Vê-se então que Free Cinema é o nome de uma série de programas exibidos no National Film Theatre de Londres entre 1956 e 1959, e também um movimento iniciado pelos diretores/curadores das mostras, além de autores do "manifesto por um cinema livre", uma reação vigorosa à estagnação do cinema inglês nos anos 1950.

A característica primordial do realismo do Free Cinema é uma preocupação com o comum e o quotidiano. Os filmes e os inúmeros textos que acompanharam os programas, além de artigos em revistas e o próprio manifesto, todos revelavam um desejo consciente de olhar para a vida do dia-a-dia das pessoas comuns e documentá-la; um desejo consciente de revelar aquilo que num primeiro momento poderia parecer insignificante, e conferir-lhe um valor cultural. Ligado a estas questões estava o desafio estético. Por escolha - ou falta de escolha - os documentários do Free Cinema foram principalmente filmados em $16 \mathrm{~mm}$, preto e branco e sem som direto, e encontraram modos alternativos de articular a realidade ao transformarem a precariedade em uma ferramenta. 
Os quatro diretores que assinaram o manifesto do Free Cinema eram jovens que iniciavam suas carreiras no cinema, mas ao contrário do que possa parecer não estavam à margem do meio cinematográfico e intelectual inglês da época. Lindsay Anderson, que estudara em Oxford e lá fundara a revista de cinema Sequence (1948-1952), escrevia à época para a importante revista do British Film Institute Sight and Sound. Karel Reisz, que além de ter escrito para a Sequence e para a Sight and Sound, tornara-se programador do National Film Theatre em 1952. Tony Richardson, outro graduado em Oxford, já tinha uma carreira sólida como diretor da BBC, e fundara em 1955 a companhia de teatro English Stage Company. Lorenza Mazzetti se mudara da Itália para Londres no início dos anos 1950, e era estudante da prestigiosa Slade School of Art. Os quatro aspirantes a diretores de cinema, um crítico, um programador, um diretor de televisão e teatro e uma estudante de arte, acabaram por se aventurar neste território na mesma época, e assim contribuíram para uma sensível mudança de rumo na história do cinema inglês no pós-guerra.

A idéia de escrever um manifesto e iniciar um movimento veio de Lindsay Anderson, que nunca negou ter articulado o Free Cinema em um primeiro momento por razões práticas, ou seja, para garantir um local para exibição dos filmes e atrair os críticos e jornalistas. Ele dizia que, devido a este espírito pragmático, o Free Cinema havia sido algo tipicamente inglês desde o início. (citado em Cinéma du Réel, 1985, p. 70) Por fim, conseguir um horário na programação do National Film Theatre revelou-se fácil por duas razões: em primeiro lugar, Karel Reisz era o seu programador, e em segundo lugar os filmes Momma Don't Allow, de Reisz e Richardson, e Together, de Mazzetti, haviam sido produzidos pelo "Experimental Film Fund" (Fundo de Cinema Experimental) do British Film Institute, instituição controladora do National Film Theatre. E assim o movimento veio à tona, impulsionado por um manifesto que era o mesmo tempo uma cínica tentativa de atrair a imprensa e uma reação genuína ao cinema britânico da época. Nas palavras de Lindsay Anderson, "todos nós pensávamos do mesmo modo, que o cinema comercial britânico era pouco ousado, preocupado apenas com as 
classes mais altas da sociedade e essencialmente desinteressante." (citado em McFarlane, 1997, p. 10)

A mostra conseguiu atrair a atenção da mídia e ganhou resenhas entusiasmadas em inúmeros jornais. O público que compareceu ao National Film Theatre nos três dias de exibição dos filmes foi muito maior do que o esperado, e o que seria apenas um programa se disseminou em outros, terminando finalmente em 1959 com o Free Cinema 6 - The Last Free Cinema. Dos seis programas, o primeiro, terceiro e sexto apresentaram exclusivamente filmes ingleses, e os outros três mostraram filmes de outros países. Eu destacaria como os principais filmes do Free Cinema os seguintes títulos: do Free Cinema 1, O Dreamland (Lindsay Anderson, 1953), Together (Lorenza Mazzetti, 1956) e Momma Don't Allow (Karel Reisz e Tony Richardson, 1956); do Free Cinema 2, Every Day except Christmas (Lindsay Anderson, 1957) e Nice Time (Claude Goretta e Alain Tanner, 1957); e do Free Cinema 6, We Are the Lambeth Boys (Karel Reisz, 1959). Cabe ainda dizer que estes filmes foram produzidos em regra com orçamentos diminutos, provenientes do próprio bolso do diretor, do "Fundo de Cinema Experimental" do British Film Institute (que através de prêmios para produção de filmes outorgava liberdade total ao diretor) ou finalmente através de um programa de incentivo ao cinema independente da "Ford Motor Company" do Reino Unido (esta também outorgando liberdade total ao diretor).

\section{Qual Realismo?}

O termo "Free Cinema" havia sido cunhado por Anderson durante a edição de um artigo para a Sequence em 1951, em referência a uma mostra de filmes experimentais americanos e canadenses organizada em Londres no mesmo ano (Cooke, 1951). Este fato já parece indicar que uma leitura cuidadosa da produção crítica de Anderson nos anos que precederam o Free Cinema, tanto para a Sequence quanto para a Sight and Sound, revela as raízes e o amadurecimento das preocupações que culminaram com o manifesto e a mostra em 1956. Na Inglaterra, a crítica cinematográfica 
adquiriu uma nova dimensão após o fim da guerra, e passou a apresentar os primeiros sinais de uma reação contra a estagnação do cinema inglês, dominado pelo dinheiro americano e com poucas exceções extremamente conservador. O termo "Free Cinema" expressava justamente estas preocupações, e indicava o desejo de Anderson em promover um rejuvenescimento ou mesmo a libertação deste cinema.

A principal linha crítica que permeava seus textos para a Sequence entre 1948 e 1952 norteava-se por uma crença no cinema como arte, em oposição ao que Anderson via como o utilitarismo do movimento documentarista dos anos 1930 e da tendência dita realista do cinema de ficção dos anos 1940. Esta preocupação teórica, que Anderson veio a manter por toda a sua vida, representou a espinha dorsal do movimento do Free Cinema, que buscou calcar um espaço dentro da cinematografia britânica para um cinema que se impunha acima de tudo como arte. Anderson e a revista Sequence também privilegiavam desde 1948 a noção do diretor como figura central de um filme, e dedicavam muitos artigos e capas a obras pessoais. Isso poderia ensejar comparações com a revista francesa Cahiers $d u$ Cinéma e a politique des auteurs. De fato, as duas revistas tiveram papéis semelhantes em seus respectivos países, levando-se em conta as diferenças de ambiente e geração. Além da importância concedida ao diretor, ambas as revistas compartilhavam um descontentamento acirrado com o estado dos cinemas inglês e francês na década de 1950. Mas não seria correto dizer que Anderson teria antecipado nas páginas da Sequence a noção do diretor-autor, posto que sempre viu o cinema acima de tudo como um esforço coletivo. Além disso, devese ter em conta que a Sequence era uma revista essencialmente anti-acadêmica e anti-teórica, favorecendo uma abordagem empírica da crítica de cinema.

Com o fim da Sequence, Anderson continuou a desenvolver seu pensamento crítico nas páginas da Sight and Sound, e intensificou sua dura condenação ao cinema inglês da época. Para ele, a grande maioria dos filmes produzidos não passava de produtos de fábrica, presos a velhas fórmulas e articulando uma versão falsa e sentimentalizada da realidade. Esta estagnação ficava patente na 
repetitiva produção de filmes de guerra, adaptações teatrais, comédias e filmes de terror. A denúncia de Anderson ganhava ainda mais força ao considerar-se o período de grande transição social e política do pós-guerra. Anderson acreditava que o cinema havia reagido de forma distante e inerte ao ambiente de mudanças, e a melhor prova disto estava em seu quase inexistente interesse pela vasta maioria da população do país: as classes trabalhadoras.

Vê-se então que o amadurecimento crítico de Anderson incorporou ao seu elogio quase apolítico do cinema como arte um movimento em defesa da crítica e do cinema socialmente comprometidos, e foi justamente a combinação destas duas crenças que orientou o movimento do Free Cinema a partir de 1956. Em resumo, Anderson advogava um novo tipo de realismo cinematográfico, voltado a uma redescoberta do dia-a-dia do homem comum, do que poderia parecer trivial e sem interesse dramático, em termos clássicos. Para Anderson, realismo era algo complexo e multifacetado, ao contrário do "realismo superficial" dos filmes das décadas de 1940 e 1950 e dos documentários da década de 1930, que apesar de parecerem progressivos na época revelaram-se com o passar do tempo essencialmente conservadores em sua propaganda social-democrática pelo esforço de guerra.

\section{Conexões}

Os escritos de Anderson também apontam para o tipo de cinema documental que ele admirava e que o influenciou no momento em que a câmera substituiu a máquina de escrever. A obra do documentarista inglês Humphrey Jennings representa sem dúvida a principal influência não apenas nos filmes de Anderson como também no Free Cinema de maneira geral. Em seu artigo "Only Connect", escrito para a Sight and Sound em 1954, Anderson afirmou que "de fato é razoável dizer que Humphrey Jennings é o único verdadeiro poeta que o cinema britânico jamais produziu." 2 (Anderson, 1954, p.

2. Texto original: "In fact it might reasonably be contended that Humphrey Jennings is the only real poet the British cinema has yet produced." 
181) Jennings iniciou sua carreira como membro da G.P.O. (General Post Office) Unit, sob a liderança de John Grierson. Entretanto, como Anderson mesmo sugeriu, "ele certamente nunca foi um documentarista tipicamente Griersoniano". ${ }^{3}$ (citado em Levin, 1971, p. 65) A produtividade de Jennings atingiu seu ápice durante a Segunda Guerra Mundial, durante a qual ele realizou uma série de filmes-propaganda, financiados pelo governo, abordando o esforço de guerra britânico e a vida quotidiana sob o ataque inimigo. London Can Take It (1940) é uma crônica da vida em Londres durante os bombardeios alemães. $\mathrm{O}$ filme se refere ao maior exército de civis jamais visto, o das pessoas comuns que enfrentam o perigo no dia-adia com dignidade e confiança. The Heart of Britain (1941) se volta para a população de regiões como Yorkshire, Derbyshire, Durham e Liverpool County. $\mathrm{O}$ forte operário de Sheffield que à noite transforma-se em vigilante, as mulheres de Liverpool que tentam manter sua rotina de trabalho com amor e devoção, o coral da igreja em Yorkshire, "todos tem o poder de resistir e assim o farão, com a habilidade de sua mãos e o fogo em seus corações", conforme nos comunica o comentário do filme. Listen to Britain (1942) segue estrutura parecida ao viajar por todo o país e mostrar a população mobilizada e unida em fazendas, fábricas, escritórios, minas de carvão, ferrovias, escolas, hospitais e salões de baile. Um filme anterior, Spare Time (1939), tratava do lazer dos trabalhadores das três principais indústrias britânicas, a do aço, a têxtil e a do carvão. $O$ filme termina na segunda-feira de manhã, com o apito da fábrica e o início da rotina semanal. Anderson notou: "Um estilo, de fato, está sendo esculpido em seus filmes; um estilo baseado na intimidade peculiar da observação, em um fascínio pela pessoa ou coisa banal, que se torna significante justamente por ser comum, e no padrão que emerge a partir do momento em que tais elementos comuns são encaixados

3. Texto original: "(...) was certainly never a typical Griersonian documentary filmmaker." 
na ordem correta." ${ }^{4}$ (Anderson, 1954, p. 182) O interesse primordial de Jennings, como se pode apreender desta rápida descrição de alguns de seus filmes, recaía sobre as pessoas comuns unidas por um espírito de solidariedade, sem preocupações informativas ou educacionais abrigadas por uma pretensa objetividade. Seu método de trabalho apoiava-se mais na observação do que em um roteiro rígido, e esta espontaneidade o distanciava do realismo educacional dominante, sendo ao mesmo tempo inovadora e inspiradora para Anderson.

$\mathrm{O}$ diretor francês Jean Vigo parece dividir com Jennings a admiração não apenas de Anderson mas dos diretores do Free Cinema em geral. Suas noções de "documentário social" e "ponto de vista documentado" parecem ter norteado a realização de vários filmes do movimento. Anderson expressou em diversos textos sua vasta admiração pela obra de Vigo, e ao descrever seu filme $O$ Dreamland no folheto de programação do Free Cinema 1 utilizou-se do termo “documentário social", cunhado por Vigo ao se referir a seu primeiro filme, A Propos de Nice, de 1929. Vigo argumentava: “O documentário social é diferente do curta-metragem comum e do noticiário filmado já que nele seu criador estabelecerá seu próprio ponto de vista." investigação satírica do resort na Riviera francesa, e explora a luxúria e a decadência da classe-média no local, com seus enormes e suntuosos hotéis, seus cassinos, suas vaidosas mulheres e seus amantes, em contraste com os mendigos e os desprovidos. O método de Vigo era também observacional, apoiando-se no procedimento de filmagem inconspícua nas ruas. Além de Anderson, os diretores de Nice Time Alain Tanner e Claude Goretta também fizeram referências diretas a Jean Vigo no programa do Free Cinema 3, declarando que

4. Texto original: "A style, in fact, is being hammered out in these films; a style based on peculiar intimacy with observation, a fascination with the commonplace thing or person that is significant precisely because it is commonplace, and with the whole pattern that can emerge when such commonplace, significant things and people are fitted together in the right order."

5. Texto original: "Social documentary is distinct from the ordinary short film and the weekly newsreel in that its creator will establish his own point of view." 
tentavam apresentar em seu filme o que Vigo chamou de "ponto de vista documentado".

\section{O Manifesto}

Conforme mencionado antes, o realismo de Anderson e do Free Cinema não pode ser reduzido a algo unidimensional, já que parece ser informado pela complexidade e pelas diversas dimensões presentes no próprio conceito de realidade. Destarte, diferentes níveis de realismo são encontrados nos filmes do Free Cinema, representando de certo modo a aplicação prática das idéias de Anderson. Trata-se, em primeiro lugar, de um realismo ideológico no que se refere à questão de classe, inextricavelmente ligado à extensão social da representação e à crítica à alienação do cinema inglês nos anos 1950. Em seguida, sua crença na inseparabilidade da forma e do conteúdo o levou a advogar um realismo estético, o que se deu nos filmes do Free Cinema através da combinação de uma escolha consciente e de uma imposição, ligada às restrições e aos avanços tecnológicos da época. Por fim, pode-se dizer que a fé no humanismo foi também determinante para a articulação do realismo de Anderson, uma indicação de seu temperamento idealístico e romântico. Distante da fachada jornalística, objetiva ou didática de muitos documentários, este realismo seria o fruto de uma preocupação com a importância de cada indivíduo. Dever-se-ia buscar a autenticidade no rosto das pessoas comuns, nos detalhes humanos capturados pela câmera, e não no coletivo.

Estes elementos estão de certa forma resumidos no manifesto que acompanhou a primeira mostra do Free Cinema:

"Estes filmes não foram realizados conjuntamente; e sem a intenção de serem mostrados conjuntamente. Mas quando reunidos, sentimos que neles havia uma mesma atitude. Implícita nesta atitude há uma crença na liberdade, na importância das pessoas e na relevância do dia-a-dia. Como cineastas nós acreditamos que nenhum filme pode ser pessoal demais. A imagem fala. $O$ 
som amplifica e comenta. O tamanho é irrelevante. Perfeição não é uma meta. Uma atitude significa um estilo. Um estilo significa uma atitude". ${ }^{6}$ (Free Cinema 1, 1956)

O termo Free Cinema pode sugerir o desejo de libertar o cinema das imposições propagandísticas e educacionais do movimento documentarista dos anos 1930, reafirmando assim a noção do filme como arte. Também poderia significar a liberdade em relação às constrições comerciais, que comprometem a expressão pessoal do diretor. "A importância das pessoas e a relevância do dia-a-dia" estão diretamente ligadas ao realismo de Anderson, que confere um valor cultural ao homem comum e ao quotidiano. A ênfase na imagem e o uso do som como contraponto está relacionada às restrições técnicas, bem como à liberdade criativa que a filmagem sem som direto pode proporcionar. "O tamanho é irrelevante" se referia principalmente à janela de projeção, menor no filme $16 \mathrm{~mm}$, em uma época em que novos formatos - principalmente o CinemaScope - eram desenvolvidos de modo a enfatizar o aspecto espetacular do cinema. Também neste sentido o manifesto declara que a "perfeição não é uma meta", referenciando uma atitude na contramão do cinema comercial, no qual grande atenção é dada a técnica. O manifesto fecha com a frase "uma atitude significa um estilo, um estilo significa uma atitude", revelando a fé de Anderson na indissolubilidade da forma e do conteúdo de um filme. Vale ainda lembrar que os programas distribuídos nas cinco mostras do Free Cinema subsequientes também continham textos inéditos, reiterando os princípios e expandindo os ideais do manifesto inicial.

6. Texto original: "These films were not made together; nor with the idea of showing them together. But when they came together, we felt they had an attitude in common. Implicit in this attitude is a belief in freedom, in the importance of people and in the significance of the everyday. As film-makers we believe that no film can be too personal. The image speaks. Sound amplifies and comments. Size is irrelevant. Perfection is not an aim. An attitude means a style. A style means an attitude." 
Curiosamente, o manifesto do Free Cinema terminava com um chamado "Envoi (Epigraph for a free cinema)", nada mais que um trecho do poema de Dylan Thomas "Our Eunuch Dreams" de 1934, finalizando em nota otimista com o verso "This is the world. Have faith." (1956, p. 15) Thomas integrou o movimento neoromântico da poesia britânica que se iniciou nos anos 1930 e chegou ao fim com sua morte em 1953. Opunha-se ferozmente aos poetas do The Movement, que por sua vez condenavam sua retórica excessiva e seu abuso de metáforas, propondo um tipo de poesia mais ligada ao quotidiano e ao homem comum. Percebe-se então que poetas do The Movement tais como Philip Larkin pareciam estar bem mais próximos do espírito do Free Cinema do que Dylan Thomas. A escolha não usual do epígrafo, portanto, parece indicar os contornos românticos do realismo destes filmes, um realismo lírico que buscava extrair poesia do dia-a-dia.

\section{O Cinema da Juventude}

Os principais filmes do Free Cinema produzidos na Inglaterra são, assim como Spare Time de Humphrey Jennings, permeados pela dicotomia que caracteriza a vida da classe trabalhadora: o trabalho e o lazer. Momma Don't Allow trata de um clube de jazz na periferia de Londres, no qual jovens trabalhadores se divertem aos sábados; $O$ Dreamland se passa em um parque de diversões no litoral, local de lazer típico da classe trabalhadora inglesa na década de 1950; Together trata do dia-a-dia de dois surdos-mudos que trabalham no porto fluvial em Londres, e vivem na região do East End, essencialmente industrial; Nice Time observa o lazer no sábado à noite nos arredores de Piccadilly Circus, no centro de Londres; Every Day except Christmas é um retrato de uma noite de trabalho no mercado de Covent Garden, em Londres; We Are the Lambeth Boys acompanha o movimento de um clube social de jovens no bairro de Lambeth, reduto da classe trabalhadora londrina na época.

Pode-se tomar como exemplo das principais características do movimento o filme Momma Don't Allow, de Tony Richardson e Karel Reisz, integrante do primeiro programa do Free Cinema. 
Momma Don't Allow é o retrato de um grupo de jovens que todos os sábados passam suas horas de lazer em um $p u b$ no norte de Londres, dançando ao som de jazz. Assim como We Are the Lambeth Boys, dirigido três anos depois por Karel Reisz, este filme exemplifica outra tendência delineada pelo Free Cinema: o desejo de retratar o aparecimento dos teenagers na década de 1950, demarcando deste modo um outro espaço que não o de classe: o espaço da juventude. O nascimento da cultura jovem foi sem dúvida um dos traços essenciais no novo panorama social do pós-guerra. O termo teenager foi importado dos Estados Unidos através do mundo da publicidade, e era uma resposta direta ao aumento do número de adolescentes e de seu poder econômico. De acordo com o impulso rejuvenescedor proposto pelo Free Cinema, que buscava uma maior aproximação com as mudanças reais no país, estes dois filmes expuseram diferentes aspectos da vida dos jovens em Londres nos anos 1950.

Os diretores Karel Reisz e Tony Richardson sempre deixaram muito clara a sua intenção de evitar a todo custo a crescente abordagem sensacionalista do universo jovem, que via os teenagers como um "problema social". O que desejavam em seus filmes era retratá-los e celebrá-los, e foi com este espírito que abordaram o fenômeno dos Teddy Boys. Comumente vistos como o primeiro movimento teenager inglês, os Teddy Boys apareceram em Londres nos anos 1950 e formavam um grupo essencialmente originário da classe trabalhadora. $\mathrm{O}$ nome Teddy Boy vem da apropriação de um estilo de vestimenta da era Edwardiana, vista como a época de ouro da aristocracia inglesa (1901 - 1910, reinado do Rei Eduardo VII). Nos anos 1950, as lojas mais sofisticadas ensaiaram um retorno a este estilo, e por uma ironia do destino os jovens trabalhadores endinheirados de Londres dele se apropriaram e passaram a ser chamados de Teddy Boys, ou Teds, já que Ted é o apelido de Edward. Eles usavam paletós mais longos do que o usual, com abas e punhos de veludo, e adicionavam outros detalhes ao estilo tais como o topete e ocasionalmente a gravata maverick. A imprensa reagiu primeiramente com desprezo, mas em pouco tempo o termo Teddy Boy se tornou sinônimo de delinqüiente juvenil. 
Momma Don't Allow, filmado em 1955, foi sem dúvida o primeiro filme inglês a mostrar os Teddy Boys e as chamadas Shop Girls - sua contrapartida feminina - sem qualquer traço de preconceito. No filme, eles e outros jovens dançam ao som da popular Chris Barber Jazz Band em um pub no norte de Londres. A banda toca o chamado trad jazz, ou jazz tradicional, estilo musical que viveu um retorno à moda nos anos 1950 entre os jovens trabalhadores ingleses, e que em seguida impulsionou a onda de skiffle, outro ritmo tradicional americano que voltava a ter grande sucesso entre os jovens. Ambos os fenômenos, tipicamente ingleses, precederam a invasão do rock ' $n$ ' roll em 1956.

O filme dura exatamente uma noite, da chegada dos músicos e o fim do dia de trabalho até a última música tocada pela banda, intitulada 'Momma Don't Allow'. As filmagens duraram nove sábados, editados de modo a parecer apenas um. O filme foi realizado com uma Bolex de corda $16 \mathrm{~mm}$, e o som - não sincronizado - foi gravado em fitas comuns. Não há diálogos ou voz over no filme, e a trilha sonora consiste apenas de som ambiente e das músicas tocadas pela banda. O fotógrafo Walter Lassally, que trabalhou em inúmeras produções do Free Cinema e mais tarde continuou a colaborar com os mesmos diretores durante o ciclo dos kitchen-sink dramas, lembra que a pequena equipe de quatro pessoas (os dois diretores, ele e o operador de som) tentava causar o mínimo de alteração, de modo a preservar a espontaneidade da atmosfera do clube. Para tanto ele não usou tripés, e as luzes - quando necessárias - eram penduradas no teto do local.

Tudo isso poderia dar a falsa impressão de que Momma Don't Allow foi realizado de modo inteiramente espontâneo. Entretanto, uma visualização atenta revela que o filme foi cuidadosamente planejado e por vezes até encenado. Com duração aproximada de 20 minutos (117 planos), os diretores ainda levaram oito meses para editar o filme, seguindo uma narrativa pré-estabelecida. Lá estão o mundo do trabalho, presente na seqüência inicial durante a qual os jovens terminam suas atividades e se preparam para sair, e o mundo do lazer, que compõe a maior parte do filme, a noite de dança na qual se esquece a rotina maçante. Em sua recriação poética da realidade, 
Momma Don't Allow articula os vários níveis de realismo que caracterizam o Free Cinema: o ideológico (foco na juventude da classe trabalhadora, com a consequiente extensão social da representação), o estético (a mobilidade do 16mm, a montagem ágil, a ausência de intenção educacional) e o humanista (o valor cultural outorgado ao indivíduo, as tonalidades românticas desalojando a objetividade). Por fim, deve-se enfatizar que a espontaneidade do filme origina-se diretamente dos jovens, que mesmo durante as seqüências de dança supostamente ensaiadas parecem não prestar atenção às filmagens e se entregam de corpo e alma à música. São seus rostos, sorrisos e movimentos de dança que contribuem para o frescor de Momma Don't Allow, nele imprimindo uma marca indelével de realidade.

\section{Uma Reação, não uma Revolução}

O Free Cinema acabou quase naturalmente em 1959, época em que os seus idealizadores Tony Richardson, Lindsay Anderson e Karel Reisz passaram para a ficção. Tony Richardson estréia na direção em 1958 com Look Back in Anger, adaptação da peça de John Osbourne que alguns anos antes havia revolucionado a paisagem teatral inglesa. Em 1960 foi a vez de Karel Reisz, que dirigiu Albert Finney em seu primeiro papel importante no cinema em Saturday Night and Sunday Morning, adaptação do romance de Allan Sillitoe sobre o dia-a-dia de um torneiro mecânico em Nottingham. Lindsay Anderson veio por último e dirigiu em 1963 outra adaptação literária, desta vez do livro de David Storey This Sporting Life. Estes e outros filmes passaram a ser chamados de kitchen-sink dramas, ou de British New Wave, e representaram um momento de inflexão extremamente importante para o cinema inglês. Alguns anos mais tarde, nas décadas de 1960 e 1970 , diretores como Ken Loach e Mike Leigh, influenciados pela geração de Anderson, passaram a dirigir filmes para a televisão quase sempre ocupados em retratar o quotidiano das parcelas menos favorecidas da população, inaugurando o chamado realismo social inglês (social realism).

Karel Reisz foi quem melhor definiu o Free Cinema ao dizer que ele representou mais uma reação do que uma revolução. $\mathrm{O}$ 
movimento surgiu em uma época de intensa transição, e acabou por integrar esta força de mudança, simbolizando o início de uma nova fase do cinema inglês. Foi também uma plataforma para novos diretores e técnicos, que puderam ousar e aprender através de filmes essencialmente livres. A aliança do Free Cinema à "relevância do dia-a-dia" parece ter sido também essencial ao desenvolvimento de uma estética e de um estilo próprios. A estrutura circular, a repetição de imagens, os movimentos mecânicos e algumas seqüências mais ousadas em termos de montagem sugerem um avanço formal importante dentro da paisagem do cinema inglês, flertando com o cinema moderno que veio a ser firmar durante a época dos cinemas novos no início dos anos 1960. Entretanto, seus traços mais conservadores observados nas produções mais tardias como o uso de voz over, a montagem convencional e por vezes um sentimentalismo exagerado acabaram por atrelar alguns filmes a um certo conservadorismo formal, do qual tentam escapar em vão.

A partir do final da década de 1960 os filmes do Free Cinema passaram a ser duramente criticados pelo seu tratamento do homem comum (Durgnat, 1969). Os três principais diretores pertenciam à classe média ou alta, haviam estudado em Oxford ou Cambridge, e por isso não teriam credibilidade para realizar filmes sobre a classe trabalhadora. Isso teria resultado em uma visão sentimentalizada do homem comum, ou em uma abordagem distanciada. A voz over em dois documentários, Every Day except Christmas e We Are the Lambeth Boys, também foi duramente criticada pelo seu tom paternalista. Com um sotaque ostensivamente da classe média, principalmente ao contrastado às vozes dos trabalhadores do Covent Garden ou dos jovens do clube em Lambeth, o comentário reforçava ainda mais a idéia de alguém alheio ao mundo observado, espreitando por trás das câmeras.

$\mathrm{Na}$ realidade, o olhar do Free Cinema nunca pretendeu ser aquele do ponto de vista interno. Sua fraqueza reside mais na indisfarçável fascinação que sente pelo trabalhador, pelo desconhecido e distante, do que em uma atitude paternalista. Neste processo de articulação, através do qual o Free Cinema se empenhou em conquistar um espaço para as classes trabalhadoras, além de um 
espaço para um cinema visto como arte dentro da cinematografia inglesa, o aspecto quotidiano de seu realismo se uniu a uma abordagem subjetiva, resultando no que escolho chamar de "realismo lírico". Pois que, como dizia Lindsay Anderson, "no fim das contas, um artista sempre faz filmes sobre si mesmo." (citado em Cinéma du Réel, 1985 , p. 72$)^{7}$

\section{Bibliografia}

ANDERSON, Lindsay. 1954. 'Only Connect: Some Aspects of the Work of Humphrey Jennings', Sight and Sound, 23 (1954), 181186

CASETTI, Francesco. 2002. Teorie del Cinema: 1945-1990. Milão: Studi Bompiani, 2002)

CATÁlogo. 1985. Catálogo da Mostra 'Cinéma du Réel: $9 e$ Festival International de Films Ethnographiques et Sociologiques' (Paris: Centre Pompidou, 1985)

CLARBE, Peter. 1997. Hope and Glory: Britain 1900-1990. London: Penguin.

COOKE, Alan. 1951. 'Free Cinema', Sequence 13, pp. 11-13

CURRAN, James e PORTER, Vincent Porter (Eds,). 1983. British Cinema Book. London: Weidenfeld and Nicolson.

DICKINSON, Margaret. ( ed.). 1999. Rogue Reels: Oppositional Filmmaking in Britain 1945-1990.London: BFI.

DURGNAT, Raymond. 1969. 'Brain Drains: Drifters, Avant-gardes and Kitchen Sinks', Cinema 3 (1969), 12-15

FELDMAN, Joseph e Harry, (eds,). Jean Vigo. (London: BFI New Index Series no. 4), [sem data], p. 5.

FREE CINEMA 1, 1956. Programa do National Film Theatre, Fevereiro 1956.

7. Texto original: "In the end an artist makes films about him self." 
HARDY, Forsyth, ed. 1946. Grierson on Documentary. London: Collins.

HILL, John. 1986. Sex, Class and Realism. London: BFI.

HOGGART, Richard. 1977. The Uses of Literacy: Aspects of Working-class Life, with Special Reference to Publications and Entertainments. Harmondsworth: Penguin.

LAING, Stuart. 1986. Representations of Working Class Life: 1957964.Basingstoke: Macmillan.

LEVIN, G. Roy. 1971. Documentary Explorations: 15 Interviews with Film-makers. New York: Doubleday \& Company.

LOVELL, Alan e HILLIER J. 1972. Studies in Documentary. London: Secker \& Warburg e BFI.

MCFARLANE, Brian. 1997. An Autobiography of British Cinema: by the Filmmakers and Actors Who Made It. London: Methuen.

RYAN, Paul, ed. 2004. Never Apologise: The Collected Writings of Lindsay Anderson. London: Plexus.

THOMAS, Dylan 1956. 'Our Eunuch Dreams' (1934), in Collected Poems 1934-1952. London: J.M. Dent \& Sons.

WILLIAMS,Raymond. 1977. 'A Lecture on Realism', Screen, 18 (1977), 61-74 